\title{
Adenocarcinoma prostático y mieloma múltiple sincrónicos: a propósito de un caso
}

\author{
Pérez López ME, García Mata J, García Gómez J, Salgado Fernández M, Fírvida Pérez JL.
}

Servicio de Oncología Médica. Complejo Hospitalario de Ourense.

Actas Urol Esp. 2007;31(2):157-159

\section{RESUMEN}

\section{ADENOCARCINOMA PROSTÁTICO Y MIELOMA MÚLTIPLE SINCRÓNICOS: A PROPÓSITO DE UN CASO}

Objetivo: Presentar un caso de carcinoma prostático sincrónico con un mieloma múltiple como inusual manifestación neoplásica. Señalar los datos clínicos que ayuden a sospechar la existencia de un mieloma en el contexto de una enfermedad metastásica ósea prostática.

Caso clínico: Paciente de 63 años diagnosticado de carcinoma prostático con diseminación ósea y buena respuesta en PSA (antígeno prostático específico) a BAC (bloqueo androgénico completo), que sufre un deterioro clínico, hipercalcemia e insuficiencia renal.

Resultados: La biopsia realizada a una masa presacra tras un nuevo estudio de extensión aporta la clave diagnóstica de un segundo tumor (mieloma).

Conclusiones: La existencia de un mieloma múltiple debe descartarse en el caso de afectación ósea diseminada prostática con lesiones líticas, buena evolución bioquímica al tratamiento y aparición de deterioro clínico, hipercalcemia e insuficiencia renal rápidamente progresiva.

Palabras clave: Metástasis óseas. Insuficiencia renal. Mieloma múltiple. Carcinoma prostático.

\section{ABSTRACT}

PROSTATE ADENOCARCINOMA AND SYNCHCRONOUS MULTIPLE MYELOMA: A CASE REPORT

Purpose: To report a case of syncrhronous prostatic cancer with multiple myeloma as inusual neoplasm presentation. To indicate the clinical data that they help to suspect the myeloma presence in the prostate bone metastatic disease.

Case report: Patient 63 years old diagnosed of prostatic carcinoma with bone metastasis and BAC good responsive, who have clinical deterioration, hypercalcemia and renal insufficiency.

Results: The presacred mass biopsy and extension study to find one second tumour (myeloma).

Conclusion: The presence of multiple myeloma must be to rule out when there are bone lytics injuries, well biochemical evolution with therapy and clinical deterioration, hypercalcemia and quickly progressive renal insufficiency.

Keywords: Bone metastases. Renal insufficiency. Multiple myeloma. Prostate carcinoma.

$\mathrm{E}^{\mathrm{s}}$ carcinoma prostático y el mieloma múltiple son dos enfermedades neoplásicas de importante prevalencia en el varón, en cierta relación con la edad. Sin embargo, la descripción sincrónica o metacrónica de ambas es anecdótica en la literatura ${ }^{1}$.
La aparición simultánea de una y otra puede que sea excepcional por su baja presentación, o quizá por la falta de un correcto diagnóstico al no sospecharse su coexistencia (ambas pueden ofrecer hallazgos analíticos y radiológicos similares). 
En el paciente descrito, afecto de un tumor prostático, se diagnostica también un mieloma múltiple al observar, además de sus metástasis óseas, un cuadro de hipercalcemia e insuficiencia renal rápidamente progresivas. Este hecho condujo a la realización de un estudio histológico de una masa de partes blandas presacra paravertebral accesible a la punción.

La singularidad de esta asociación, la falta de hallazgos en la literatura y su bajo índice de sospecha en la práctica clínica, nos ha animado a su presentación.

\section{CASO CLÍNICO}

Paciente de 63 años diagnosticado en los tres meses previos a su ingreso de adenocarcinoma prostático bien diferenciado Gleason $1+1$, estadio IV (metástasis óseas), a raíz de una consulta por síndrome prostático y dolores óseos generalizados. Se le realizaron en esa fecha: PSA, biopsia prostática, y gammagrafia ósea que evidenciaba lesiones blásticas en escápula, hombro y costillas. Se le instauró tratamiento con bloqueo androgénico completo (BAC) objetivándose en un control analítico posterior, normalización del PSA.

Al cabo de los tres meses citados anteriormente, el enfermo acude a urgencias por dolores óseos severos, de predominio en columna lumbar, hipercalcemia e insuficiencia renal, que no presentaba previamente.

Inicialmente se instaura tratamiento con analgesia a demanda, fluidoterapia, ácido zoledrónico, corticoides y diuréticos.

Se realiza una TAC abdómino-pélvica que evidencia una próstata moderadamente agrandada, un quiste cortical renal derecho incidental, lesiones líticas vertebrales dorsales y lumbares, costales y en ala sacra izquierda que se asocian a una masa de partes blandas (Fig. 1).

En la analítica persistía una normalización del PSA, cierto grado de insuficiencia renal (Creatinina 1.8), normalización de la calcemia después de tratamiento específico y proteinuria en orina de 24 horas.

Ante la alta sospecha clínica de mieloma múltiple en un paciente con buena evolución bioquímica al BAC en su carcinoma prostático, su gran deterioro clínico y radiológico y la aparición de insuficiencia renal, se decide la citopunción de la masa de partes blandas sacra.

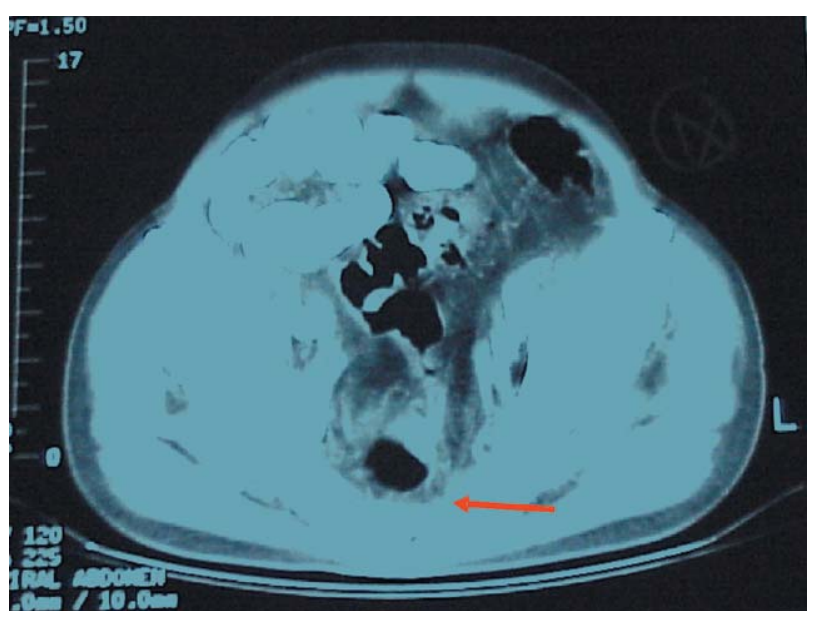

FIGURA 1: Masa de partes blandas presacra.

La citología de la misma fue positiva para mieloma múltiple, confirmándose posteriormente con la realización de una biopsia de médula ósea.

Se inició tratamiento con melfalán y corticoides, manteniéndose el BAC, con mala respuesta en su enfermedad hematológica. Posteriormente se sustituyó por el régimen VAD (Vincristina, Adriamicina y dexametasona) y BAC con gran mejoría. A los 3 meses se realizó de nuevo biopsia de médula ósea de control, valorándose una respuesta histológica importante en la infiltración por el mieloma.

En al actualidad el paciente mantiene tratamiento de quimioterapia según esquema citado anteriormente y BAC con buena evolución, manteniéndose normalización de PSA, calcemia y función renal.

\section{DISCUSIÓN}

La asociación de dos neoplasias simultáneas en un mismo paciente no es un hecho aislado; puede ser fruto del azar, de una predisposición genética y/o individual o de una exposición a agentes carcinogénicos.

Es también conocido el aumento de la incidencia de segundos tumores, generalmente del sistema hematopoyético en pacientes expuestos a quimioterapia con agentes alquilantes o radioterapia en el tratamiento del cáncer inicial ${ }^{2}$.

El diagnóstico sincrónico o metacrónico (intervalo entre su aparición menor o mayor de 6-12 meses, respectivamente) de un tumor sólido y un mieloma múltiple en un mismo paciente es muy 
baja $^{3}$ (aunque el mayor índice de sospecha y la mejora de las técnicas diagnósticas ha incrementado su detección en los últimos años) ${ }^{4}$. Las localizaciones más frecuentes son: cabeza y cuello, intestino grueso, mama y pulmón ${ }^{3}$.

En el caso relatado, el diagnóstico de sospecha se realizó ante la progresión clínica (aumento del dolor y deterioro del estado general), analítica (aumento de calcio y creatinina) y radiológica (aparición de lesiones líticas, cuando sólo se evidencianban lesiones blásticas previamente), con una normalización del PSA después del bloqueo androgénico completo (BAC).Todos estos hallazgos son inespecíficos ${ }^{1,5} \mathrm{y}$ también podrían presentarse en la enfermedad metastásica prostática ${ }^{6,7}$.

La existencia de una masa de partes blandas sacra accesible, la observación de una insuficiencia renal progresiva y la verificación de proteinuria en orina de 24 horas, condujo a la realización de una punción citológica de la primera, que fue diagnóstica de mieloma múltiple. Posteriormente se confirmó con la biopsia de médula ósea.

En resumen, este caso nos ha sugerido que, ante una insuficiencia renal rápidamente progresiva y una enfermedad metástasica de predominio lítico, en un paciente con carcinoma prostático y buena respuesta bioquímica a BAC, puede sospecharse un mieloma múltiple subyacente.

\section{REFERENCIAS}

1. Huang E, Teh BS, Saleem A, Butler B. Recurrence of prostate adenocarcinoma presenting with multiple myeloma simulating skeletal metastases of prostate adenocarcinoma. Urology 2002;60(6): 1111.

2. Van Leeuven F. Second cancers en: De VITA 5 ed. Cancer, Principles and practice of oncology. Philadelphia- N.Y. Lippincott-Raven;1997.p. 2773-2792.

3. Calvo JM, Ramírez MJ, Cuesta J y Sicilia FJ. Mieloma múltiple y carcinoma de pulmón de células pequeñas. Rev Clin Esp 2001;201:294-295.

4. Todolí JA, Campo C, Segura A, et al. Asociación de mieloma múltiple y neoplasias sólidas: análisis de trece casos. Rev Clin Esp 1999;199:725-728.

5. Maharaj B, Kalideen JM, Leary WP and Pudifin DJ. Carcinoma of the prostate with multiple osteolytic metastases simulating multiple myeloma. A case report. S Afr Med J. 1986;16;70(4):227-228.

6. Marlier S, Durupt S, de Jaureguiberry JP, Marlier-Civatte M, Peybere B Jaubert D. Bone and bone marrow metastases of prostatic carcinoma: the serum level of prostatespecific antigen may be normal. Presse Med 1996;4-11;25 (16): 777 .

7. Hollemberg GM. Extraosseous multiple myeloma simulating primary prostatic neoplasm. J Urol 1978;119(2):292-294.

Correspondencia autor: Dra. M $\mathrm{M}^{\mathrm{a}}$ Eva Pérez López.

Servicio de Oncología Médica. Complejo Hospitalario de Ourense. C/ Ramón Puga 54-56. 32005 Ourense.

Telf.: 981.17.80.00 / Ext. 11.163.

E-mail autor: mevaplo@hotmail.com

Información artículo: Nota clínica

Trabajo recibido: enero 2006

Trabajo aceptado: febrero 2006 